\title{
Screening and Identification of SSR Markers for Genetic Diversity for Mungbean [Vigna radiata (L.) Wilczek]
}

\author{
M. Kanimoli Mathivathana ${ }^{1 *}$, N. Jagadeeshselvam², B. Madhumitha ${ }^{3}$, \\ A. Karthikeyan ${ }^{4}$, M. Pandiyan ${ }^{5}$, G. Karthikeyan ${ }^{6}$, C. Vanniarajan" ${ }^{1}$, \\ M. Raveendran ${ }^{2}$, N. Senthil ${ }^{* *}$ and M. Sudha ${ }^{2^{*}}$
}

${ }^{1}$ Department of Plant Breeding and Genetics, Agricultural College and Research Institute, Madurai, Tamil Nadu Agricultural university, Tamil Nadu, India

${ }^{2}$ Department of Plant Biotechnology, Center for Plant Molecular Biology and Biotechnology,

Tamil Nadu Agricultural university, Coimbatore, Tamil Nadu, India

${ }^{3}$ Department of pathology, Agricultural College and Research Institute, Tamil Nadu

Agricultural University, Madurai, Tamil Nadu, India

${ }^{4}$ Department of Biotechnology, Agricultural College and Research Institute, Tamil Nadu

Agricultural University, Madurai, Tamil Nadu, India

${ }^{5}$ Agricultural College and Research Institute, Tamil Nadu Agricultural University, Eachangkottai, Tamil Nadu, India

${ }^{6}$ Department of Plant Pathology, Center for Plant Protection Studies, Tamil Nadu Agricultural University, Coimbatore, Tamil Nadu, India

*Corresponding author

\section{A B S T R A C T}

\section{Keywords}

Genetic diversity, SSR, Polymorphism, Mungbean, Molecular markers

Article Info

Accepted:

07 March 2018

Available Online:

10 April 2018
Mungbean (Vigna radiata) is an economically important pulse crop and is an excellent source of easily digestible proteins with low flatulence which complements the staple rice diet in Asia and particularly in India. Information about mungbean germplasm diversity and genetic relationships among accessions or cultivars is of fundamental importance for breeding and the management of germplasm. To study genetic diversity at molecular level different types of DNA markers can be used. Among the different DNA markers, simple sequence repeat (SSR) markers are highly variable in the genome, also reproducible and cost effective. A total of ten SSR primers that showed stable amplification was used to explore the diversity in six mungbean genotypes. Of these, two SSR primers VrSSR_6_ 746 and VrSSR_1_31 showed polymorphism in the six mungbean genotypes, while the remaining were monomorphic. Collectively, the results of present study can be helpful in planning the utilization patterns and management of mungbean genotypes. 


\section{Introduction}

Mungbean [Vigna radiata (L.) R. Wilczek var. radiata] is a grain legume originating from South Asia. It is a self-pollinated diploid species with a chromosome number of $2 \mathrm{n}=22$ with an estimated genome size of 543 mega bases (Mb) (Parida et al., 1990; Kang et al., 2014). The crop is originated in India and predominantly grown in China, India, Pakistan and Thailand (Karthikeyan et al., 2014). Mungbean is a warm seasonal annual legume, grown mostly as a rotational crop with cereals like wheat and rice ( $\mathrm{Li}$ et al., 2009 and Aggarwal et al., 1992). It is well suited to a large number of cropping systems and constitutes an important source of cereal based diets, worldwide, covering more than six million hectares per annum. However, Asia, alone, accounts for $90 \%$ of world's mungbean production. India is the world's largest mungbean producer accounting for about $65 \%$ of world's acreage and 54\% of its global production (Singh, 2011). Mungbean contains carbohydrate $(51 \%)$, protein $(24 \%-26 \%)$, minerals (4\%) and vitamins (3\%) (Karthikeyan et al., 2014). Diverse uses of mungbean make it a more widely desired crop plant and are rapidly increasing its demand. Therefore improvement in nutrient content and grain yield remains most important breeding objective in mungbean. Genetic diversity is the base for crop genetic improvement and important for the conservation, evaluation and utilization of crop germplasms (Rao and Hodgkin 2002; Wang et al., 2015 and Anumalla et al., 2015). The assessment of genetic diversity will predict the phylogeny and evolution of species and to characterize genotypes (Simon et al., 2007 and Iseki et al., 2016). So far very limited work has been done for the genetic improvement of mungbean crop and continuous to be neglected compare to the other major legume crops such as soybean, cowpea and common bean, or even with comparison with one of its relative, but the less economically important, azuki bean.

Morphological traits are routinely used for estimating the genetic diversity and it is the predominant tool for breeding practices (Lestari et al., 2014; Gokulakrishnan et al., 2012 and Wang et al., 2017). The genetic diversity within the genotypes of mungbean based on the morphological trait is comparatively low because it is predominantly self-pollinating (Sudha et al., 2015). Due to this issue, recently DNA markers such as restriction fragment length polymorphism (RFLP), random amplified polymorphic DNA (RAPD), amplified fragment length polymorphism (AFLP) and simple sequence repeats (SSRs) were used to assess the genetic diversity in many crop species including mungbean (Chen et al., 2015; Liu et al., 2013; Wang et al., 2006; Ferreira et al., 2016 and Zia et al., 2014). With this background knowledge, the main aim of the present study was to investigate and compare genetic diversity using simple sequence repeats (SSR) markers, for assessing the genetic base of released genotypes of mungbean.

\section{Materials and Methods}

\section{Plant material}

A total of six mungbean genotypes viz., VGGRU1, VRM(Gg)1, $\mathrm{CO}(\mathrm{Gg}) 8, \mathrm{CO}(\mathrm{Gg}) 6$, $\mathrm{CO}(\mathrm{Gg}) 7$ and $\mathrm{VBN}(\mathrm{Gg}) 2$, used in this study were grown in green house at Department of Biotechnology, Center for Plant Molecular Biology and Biotechnology, Tamil Nadu Agricultural University, Coimbatore. Tamil Nadu, India.

\section{DNA extraction}

The six mungbean genotypes were used for DNA isolation using CTAB method as described by sudha et al., (2009). Briefly, the 
leaf tissues from 10-day old seedlings from these mungbean genotypes were sliced into small bits of 1-2 cm long and transferred to 2 $\mathrm{ml}$ eppendorf tubes along with two beads per tube. About $500 \mu \mathrm{l}$ of pre-heated extraction buffer (2\% CTAB mM, Tris-HCL pH 8.0, 50 mM EDTA pH 8.0, 1.5 M NaCl) was added to the leaf tissues and mixed well by vortexing and inverting. The tubes were placed in a 60 ${ }^{0} \mathrm{C}$ water bath in a tube holder for $20 \mathrm{~min}$ with occasional mixing. Equal volume of Chloroform: Isoamyl alcohol mix (24:1) was added to the tubes with the samples and mixed by repeated inversion for $3 \mathrm{~min}$. The tubes were centrifuged at $12,000 \mathrm{rpm}$ at $4^{0} \mathrm{C}$ for 20 min. After centrifugation, the upper aqueous phase was collected. Equal volume of Phenol: Chloroform (1:1) was added to the tubes with the samples and mixed by repeated inversion for $3 \mathrm{~min}$. The tubes were centrifuged at $12,000 \mathrm{rpm}$ at $4{ }^{\circ} \mathrm{C}$ for $20 \mathrm{~min}$. After centrifugation, the upper aqueous phase was collected and equal volume of ice cold isopropanol was added to the tubes. The tubes were incubated at $-20^{\circ} \mathrm{C}$ for overnight. The tubes were centrifuged at $12,000 \mathrm{rpm}$ at $4{ }^{\circ} \mathrm{C}$ for $20 \mathrm{~min}$. discard the solution from the tube after centrifuge. The DNA pellets were washed with $70 \%$ ethanol and centrifuge the tube at $10,000 \mathrm{rpm}$ for $7 \mathrm{~min}$. Discard the solution then kept it for air dry. Dissolve the DNA pellet in sterile water or TE buffer. After dissolving the pellet, the concentrated DNA was stored at $-20^{\circ} \mathrm{C}$. DNA concentration and purity based on A260/A280 ratios was quantified using a Nano- Drop spectrophotometer (ND-1000 Spectro photometer, NanoDrop Technologies, and USA) and the DNA concentration was normalized to be $25 \mathrm{ng} / \mu \mathrm{l}$ for PCR reaction.

\section{SSR assay}

A standard PCR reaction were performed in $15.00 \mu \mathrm{l}$ volume containing $25 \mathrm{ng}$ of template DNA, 3 units $/ \mu$ of Taq DNA polymerase
(Bangalore Genei Ltd., Bangaluru, Karnataka, India) $1.50 \mu \mathrm{l}$ of $10 \mathrm{X}$ of assay buffer, $2.5 \mathrm{mM}$ of dNTPs, $0.5 \mu \mathrm{M}$ each of forward and reverse primers was performed in MyCycler (BioRAD, USA) with the following PCR conditions: DNA denaturation at $94{ }^{\circ} \mathrm{C}$ for 7 min, 40 cycles of $94{ }^{\circ} \mathrm{C}$ for 30s, primer annealing at $55{ }^{\circ} \mathrm{C}$ for $30 \mathrm{~s}$ and a primer extension step of $72{ }^{\circ} \mathrm{C}$ for $45 \mathrm{~s}$ and final elongation step was extended to $72{ }^{\circ} \mathrm{C}$ for 7 min. The PCR products were resolved in a gel electrophoresis on 3.5\% agarose gels for SSR at $80 \mathrm{~V}$. The gel were pre stained with ethidium bromide and visualized on a digital gel documentation and image analysis system (Alpha Imager 1200, Alpha Innotech Corp., USA)

\section{Results and Discussion}

SSR markers, an excellent molecular marker system with the advantages of being codominant, abundant, highly reproducible, highly polymorphic, and easy to assay, have been used in diversity assessment of germplasm (Chen et al., 2015; Liu et al., 2013). The present study described the existing genetic diversity in six mungbean genotypes using SSR markers. Preliminary screening was performed to set up standardized PCR conditions and estimate the allele size range. PCR amplification condition was standardized by varying $\mathrm{MgCl}_{2}$ and Taq DNA polymerase unit and temperature of amplification (Ta) for each primer pair was also standardized using gradient PCR. Out of the tested 10 SSR primers, DNA amplification was obtained in all the ten primers and yielded PCR products of the expected fragment size (200-300 bp). Further, we used the 10 SSR primer pairs that showed stable amplification to explore the polymorphism in six mungbean genotypes. Of these primers: VrSSR_6_ 746 and VrSSR_1_31, showed polymorphism in the six mungbean genotypes (Fig. 1), while the remaining were monomorphic. 
Fig.1 PCR amplification for SSR marker VrSSR_6_746 and VrSSR_1_31 in mungbean genotypes (Note: M- Marker 100bp, genotypes details (1-6: VGGRU1, VRM(Gg)1, CO(Gg)8, $\mathrm{CO}(\mathrm{Gg}) 6, \mathrm{CO}(\mathrm{Gg}) 7$ and $\mathrm{VBN}(\mathrm{Gg}) 2)$

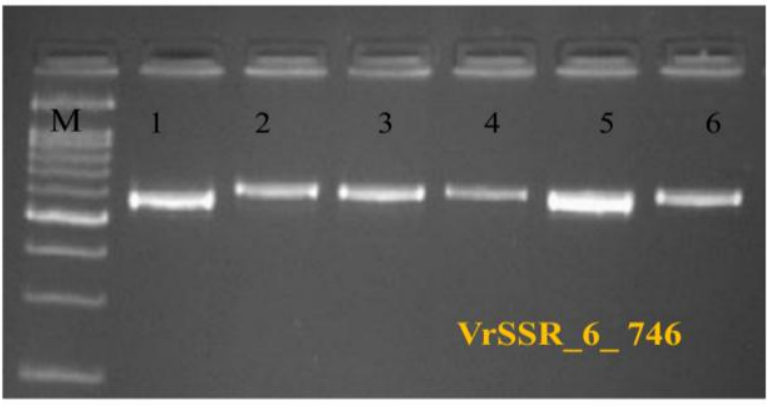

The sequence data of the polymorphic SSR marker are VrSSR_6_ 746 have (forward primer 5'TGTGTCCTCCGAGACTCTCA3' and reverse primer 5'ACGAATGTGATACC GTGCAA3') and VrSSR_1_31 have (forward primer 5' CACCTTGCACGTCCTCAAC3' and reverse primer (5, TCCAGTCCCTCATC CCTTCA3'). These results suggest that SSR markers can be used as the more accurate and efficient tool for the differentiation among mungbean genotypes. Mainly in plants genetics, on the application of SSR markers, many publishing over the years (Chen et al., 2015 and Liu et al., 2013). Association of conventional breeding programs with modern agricultural practices has been responsible for the shrinkage of genetic diversity for many cultivated species. In summary, the molecular markers obtained in the present study are identified specific for the particular line. Therefore it could be beneficial for plant breeders for the utilization and improvement of the genotypes.

\section{Conflict of Interest}

The authors declare that the research was conducted in the absence of any commercial or financial relationships that could be construed as a potential conflict of interest.

\section{Acknowledgement}

This work was financially supported through grants from the Department of Biotechnology,

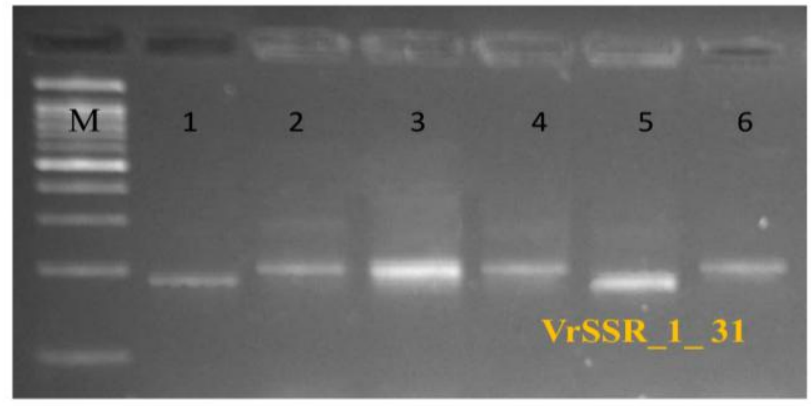

GOI (BT/PR5095/AGR/2/847/2012, Phase: II, Dt 27-5-2015). The funders had no role in work design, data collection and analysis, or decision and preparation of the manuscript.

\section{References}

Aggarwal, P.K., Garrity, D.P., Liboon, S.P. and Morris, R.A. 1992. Resource use and plant interactions in a rice-mungbean intercrop. Agron J., 84:71-78.

Anumalla, M., Roychowdhury, R., Geda, C.K., Mazid, M. and Rathoure, A.K. 2015. Utilization of Plant Genetic Resources and Diversity Analysis Tools for Sustainable Crop Improvement with special emphasis on Rice. International Journal of Advanced Research, 3(3): 1155-1175.

Chen, H.L., Qiao, L., Wang, L.X., Wang, S.H., Blair, M.W. and Cheng, X.Z. 2015. Assessment of genetic diversity and population structure of mung bean (Vigna radiata) germplasm using EST based and genomic SSR markers. Gene, 566: 175183.

Ferreira, J.R., Pereira, J.F., Turchetto, C., Minella, E., Consoli, L. and Delatorre, C.A. 2016. Assessment of genetic diversity in Brazilian barley using SSR markers. Genet Mol Biolv., 39(1).

Gokulakrishnan, J., Sunil Kumar, B. and Prakash, M. 2012. Studies on genetic 
diversity in mung bean (Vigna radiata L.). Legume Research, 35(1):50-52.

Iseki, K., Takahashi, Y., Muto, C., Naito, K. and Tomooka, N. 2016. Diversity and Evolution of Salt Tolerance in the Genus Vigna. PLOS ONE., pp: 1-21.

Kang, Y.J., Kim, S.K., Kim, M.Y., Lestari, P., Kim, K.H., Ha, B., et al., (2014). Genome sequence of mungbean and insights into evolution within Vigna species. Nat. Commun. 5, 1-9.

Karthikeyan, A., Shobhana, V. G., Sudha, M., Raveendran, M., Senthil, N., Pandiyan, M., and Nagarajan, P. (2014). Mungbean yellow mosaic virus (MYMV): a threat to green gram (Vigna radiata) production in Asia. Int. J. Pest Manag. 60, 314-324.

Lestari, P., Kim, S.K., Reflinur, Kang, Y.J., Dewi, N. and Lee, S.H. 2014. Genetic diversity of mungbean (Vigna radiata $\mathrm{L}$.) germplasm in Indonesia. Genomics of Plant Genetic Resources: pp. 91-94.

Li, Y., Wei, L., Ruiping, R., Shubin, Z. and Xu, S.G. 2009. Facilitated legume nodulation, phosphate uptake and nitrogen transfer by arbuscular inoculation in an upland rice and mung bean intercropping system. Plant and Soil, 315(1-2): 285-296.

Liu, Y., Cheng, X.Z., Wang, L.X., Wang, S.H., Bai, P. and $\mathrm{Wu}$, C.S. 2013. Genetic diversity research of mung bean germplasm resources by SSR markers in China. Sci. Agric. Sin., 46: 4197-4209 (in Chinese with English abstract).

Parida A., Raina S., Narayan R. (1990). Quantitative DNA variation between and within chromosome complements of Vigna species (Fabaceae). Genetica 82 125-133.

Rao, V.R. and Hodgkin, T. 2002. Genetic diversity and conservation and utilization of plant genetic resources. PCTOC, 68(1): 1-19.

Simon, M.V., Benko-Iseppon, A.M., Resende, L.V., Winter, P. and Kah, G. 2007. Genetic diversity and phylogenetic relationships in Vigna Savi germplasm revealed by DNA amplification fingerprinting. Genome, 50(6): 538-547.

Singh BB. 2011. Project coordinators report. All India Coordinated Research Project on MULLaRP. Annual Group Meet; 1113 May 2011; Kanpur: Indian Council of Agricultural Research, Indian Institute of Pulses Research.

Sudha, M., (2009). DNA isolation protocol for Vigna radiata with free of phenolics. Nature protocols. 167.

Wang, L.X., Guan, R.X., Liu, Z.X., Chang, R.Z. and Qiu, L.J. 2006. Genetic diversity of Chinese cultivated soybean revealed by SSR markers. Crop Sci., 46: 1032-1038.

Wang, Y., Shahid, M.Q., Ghouri, F., Baloach, F.S., Wang, Y. and Huang, H. 2015. Evaluation of the geographical pattern of genetic diversity of Glycine soja and Glycine max based on four single copy nuclear gene loci: For conservation of soybean germplasm., Biochemical Systematics and Ecology., 62; 229-235.

Wanga, L., Baib, P., Yuan, X., Chen, H., Wang, S., Chen, X. 2017. Genetic diversity assessment of a set of introduced mung bean accessions (Vigna radiata L.). The Crop Journal, pp: 1-7.

Zia, Z.U., Sadaqat, H.A., Tahir, M.H.N., Sadia, B., Bushman, B.S., Hole, D., Michaels, L. and Malik, W. 2014. Estimation of genetic diversity using SSR markers in sunflower. Russian Journal of Genetics, 50(5): 498-507.

\section{How to cite this article:}

Kanimoli Mathivathana, M., N. Jagadeeshselvam, B. Madhumitha, A. Karthikeyan, M. Pandiyan, G. Karthikeyan, C. Vanniarajan, M. Raveendran, N. Senthil and Sudha, M. 2018. Screening and Identification of SSR Markers for Genetic Diversity for Mungbean [Vigna radiata (L.) Wilczek]. Int.J.Curr.Microbiol.App.Sci. 7(04): 789-793. doi: https://doi.org/10.20546/ijcmas.2018.704.088 